\title{
Imaging Bone Metastases in Breast Cancer: Staging and Response Assessment
}

\author{
Gary J.R. Cook, Gurdip K. Azad, and Vicky Goh \\ Cancer Imaging Department, Division of Imaging Sciences and Biomedical Engineering, Kings College London, London, England
}

Bone metastases are common in patients with advanced breast cancer. Given the significant associated morbidity, the introduction of new, effective systemic therapies, and the improvement in survival time, early detection and response assessment of skeletal metastases have become even more important. Although planar bone scanning has recognized limitations, in particular, poor specificity in staging and response assessment, it continues to be the main method in current clinical practice for staging of the skeleton in patients at risk of bone metastases. However, the accuracy of bone scanning can be improved with the addition of SPECT/CT. There have been reported improvements in sensitivity and specificity for staging of the skeleton with either bone-specific $\mathrm{PET} / \mathrm{CT}$ tracers, such as ${ }^{18} \mathrm{~F}-\mathrm{NaF}$, or tumor-specific tracers, such as ${ }^{18} \mathrm{~F}-\mathrm{FDG}$, although these methods are less widely available and more costly. There is a paucity of data on the use of ${ }^{18} \mathrm{~F}-\mathrm{NaF}$ $\mathrm{PET} / \mathrm{CT}$ for response assessment in breast cancer, but there is increasing evidence that ${ }^{18} \mathrm{~F}-\mathrm{FDG}$ PET/CT may improve on current methods in this regard. At the same time, interest and experience in using whole-body morphologic MRI augmented with diffusionweighted imaging for both staging and response assessment in the skeleton have been increasing. However, data on comparisons of these methods with PET methods to determine the best technique for current clinical practice or for clinical trials are insufficient. There are early data supporting the use ${ }^{18} \mathrm{~F}-\mathrm{FDG}$ PET/MRI to assess malignant disease in the skeleton, with the possibility of taking advantage of the synergies offered by combining morphologic, physiologic, and metabolic imaging.

Key Words: bone scanning; oncology; skeletal metastases; PET; PET/CT; SPECT

J Nucl Med 2016; 57:27S-33S

DOI: 10.2967/jnumed.115.157867

$\mathbf{T}$ he skeleton is the most common site for metastases from breast cancer, being affected in approximately $50 \%-70 \%$ of patients with relapse $(1,2)$, and is the sole site of disease in $28 \%-$ $44 \%(3,4)$. Skeletal metastases cause significant morbidity, including pain, fractures, hypercalcemia, and spinal cord compression; patients in whom disease is confined to the skeleton have the greatest risk of skeleton-related events (5). The median survival of patients with disease confined to the skeleton is relatively long com-

Received Aug. 3, 2015; revision accepted Aug. 6, 2015.

For correspondence or reprints contact: Gary J.R. Cook, Clinical PET Centre, St. Thomas' Hospital, London SE1 7EH, United Kingdom.

E-mail: gary.cook@kcl.ac.uk

COPYRIGHT (C) 2016 by the Society of Nuclear Medicine and Molecular Imaging, Inc. pared with that of patients with visceral disease ( $2.2 \mathrm{y}$ vs. $5.5 \mathrm{mo}$; $P<0.001$ ) (3); therefore, cumulative morbidity and health care costs from bone metastases are high. With the arrival of effective novel therapies, it has become even more important to detect bone metastases at an early stage to minimize skeleton-related events and to allow the determination of a response as early as possible to limit toxicity and accelerate the therapeutic transition in nonresponding patients.

Imaging has always played a key role in the diagnosis of bone metastases in breast cancer and planar ${ }^{99 \mathrm{~m}} \mathrm{Tc}$-diphosphonate bone scanning (BS) remains widely used, its lack of specificity has been improved with the addition of SPECT and SPECT/CT. At the same time, there has been an increase in the use of other hybrid techniques for imaging of the skeleton (e.g., PET/CT) as well as whole-body MRI techniques, which have improved sensitivity. Despite improved accuracy in staging of the skeleton, evidence of efficacy and consensus regarding effective monitoring of a treatment response are lacking. Although radiographs have been used historically to determine a response by lesion resolution or sclerosis $(6,7)$, this method has been recognized as being insensitive and may take at least 6 mo to yield a confident assessment of a response.

RECIST 1.1 (8) depends primarily on a change in longitudinal dimension in nodal and visceral disease. Only lytic bone metastases with soft-tissue masses of greater than $1 \mathrm{~cm}$ (an infrequent finding) are deemed measureable; although the use of BS, PET, or radiography for confirmation of a complete response is permitted, most bone metastases are not assessable. A more pragmatic approach involving a combination of imaging results from BS, CT, and radiography has been shown to provide a better prediction of progression-free survival and overall survival than World Health Organization criteria but has not yet gained wide acceptance (9). When these criteria were prospectively tested in 29 breast cancer patients with bone-only metastases, they were found to predict progression-free survival at $6 \mathrm{mo}$ but not $3 \mathrm{mo}$, similar to the World Health Organization criteria (10).

The purpose of this review is to update the current status of imaging, particularly BS, ${ }^{18} \mathrm{~F}-\mathrm{FDG}$ PET, and ${ }^{18} \mathrm{~F}-\mathrm{NaF}$ PET, for detection and therapy response monitoring of bone metastases from breast cancer. Some potential future methods that show promise are also discussed.

\section{PATHOPHYSIOLOGY OF BONE METASTASES}

Paget suggested that metastases depend on cross talk between cancer cells ("seeds") and specific organ microenvironments ("the soil") (11). Bone marrow stromal cells attract tumor cells through the expression of chemotactic molecules and provide the tumor cells with an environment in which to grow. The abilities of cancer cells to adhere to bone matrix and to promote osteoclast maturation 
and activity are important in the development of bone metastases. Untreated bone lesions exist on a spectrum between predominantly osteoblastic (e.g., prostate cancer-related skeletal metastases) and osteolytic (e.g., myeloma), but breast cancer metastases can vary between the two or can be mixed in the same patient. The phenotypes have different effects on bones and may influence the selection of the optimal imaging modality for demonstrating the lesions.

In bone metastases that are predominantly osteolytic, parathyroid hormone-related protein, derived from cancer cells, stimulates production of the receptor activator of nuclear factor $\mathrm{\kappa B}$ ligand; the latter leads to osteoclast maturation and bone resorption that outstrips attempts at osteoblastic bone formation and repair (12). Of relevance, a human monoclonal antibody to the receptor activator of nuclear factor $\kappa \mathrm{B}$ ligand, denosumab, is currently being used in the treatment of cancer-related bone disease, and bisphosphonates exert some of their effect by inhibiting osteoclasts. Tumor cells can also secrete several growth factors that stimulate bone formation through increased osteoblastic activity (12). This primary osteoblastic activity may be indistinguishable on imaging from reactive and reparative osteoblastic activity that follows successful treatment of both osteolytic and osteoblastic bone metastases.

\section{BONE SCINTIGRAPHY, INCLUDING SPECT AND SPECT/CT}

BS has been used for decades as the primary method for staging and response assessment of skeletal metastases. Despite recognized limitations with regard to diagnostic specificity and both sensitivity and specificity in measuring a treatment response, BS remains in widespread use in clinical practice. Abnormal accumulation of ${ }^{99 m}$ Tc-labeled diphosphonates is related to changes in local blood flow and osteoblastic activity (13), events that are secondary in most bone metastases that are seeded in the bone marrow. Although BS is still considered a sensitive technique, methods that can detect tumor in the bone marrow, such as ${ }^{18} \mathrm{~F}-\mathrm{FDG}$ PET and MRI, before osteoblastic activity is present-particularly in predominantly osteolytic disease-have been shown to be even more sensitive (14-18). The

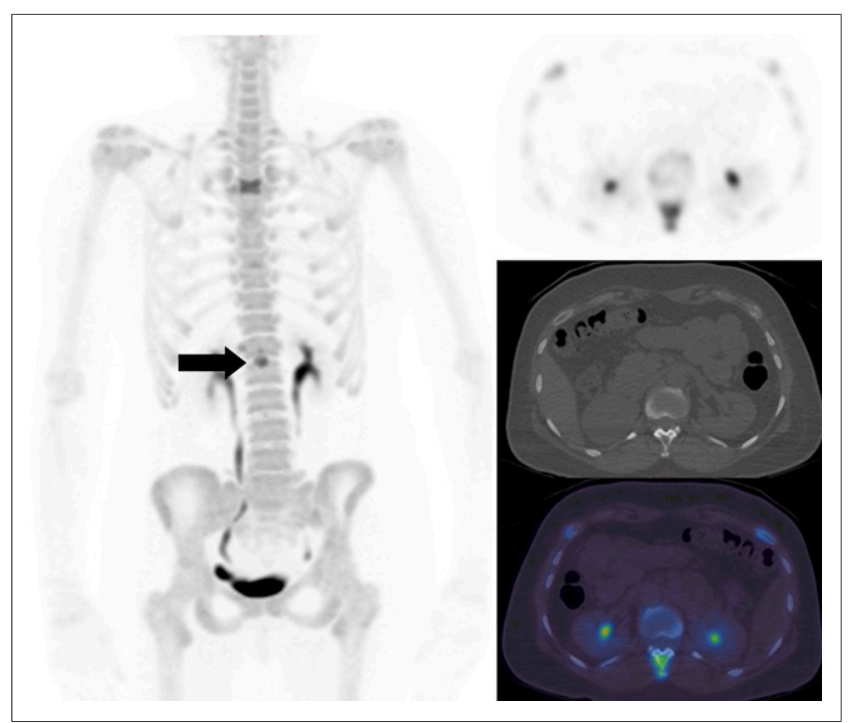

FIGURE 1. A 48-y-old woman with metastatic breast cancer. Maximum-intensity projection ${ }^{18} \mathrm{~F}-\mathrm{NaF}$ (left) and axial ${ }^{18} \mathrm{~F}-\mathrm{NaF} \mathrm{PET}, \mathrm{CT}$, and fused PET/CT slices (right, from top to bottom) at level of T12 showing a metastasis in the spinous process (arrow). A further metastasis is visible at $\mathrm{T} 4$. mechanism of accumulation means that the uptake of ${ }^{99 m}$ Tc-labeled diphosphonates is not specific for metastatic disease and may also make the differentiation of increased reparative osteoblastic activity after successful treatment (flare) from unresponsive progressive disease impossible for several months.

For staging of the skeleton, some improvements in sensitivity and specificity were observed when BS was augmented with SPECT (19-21). Further gains in sensitivity and, especially, in specificity and diagnostic confidence were apparent with SPECT/CT (22-25) because of the greater contrast resolution of SPECT coupled with the ability to reduce false-positive diagnoses of metastases through correlation with the morphologic appearance of lesions on CT.

For response assessment, the limitations of BS in defining response or nonresponse have been recognized for many years, with only $52 \%$ of responders showing scintigraphic improvement and $62 \%$ of nonresponders showing scintigraphic deterioration at 6-8 mo in an early study (26). The problem of the flare phenomenon, which makes the differentiation of progression from a temporary healing osteoblastic response to successful therapy difficult for 3-6 mo, has also been recognized for many years and has been described after chemotherapy and endocrine therapy in breast cancer $(27,28)$. However, if serial scans confirm a flare, then a successful response can be predicted (29). Nevertheless, a time lag of 3-6 mo for accurate response evaluation from the start of treatment limits the utility of BS for response evaluation in routine clinical practice or as a progression endpoint in clinical trials, and we are not aware of evidence that shows an improvement through the addition of SPECT or SPECT/CT in such situations.

\section{${ }^{18} \mathrm{~F}-\mathrm{NaF}$ PET}

${ }^{18} \mathrm{~F}-\mathrm{NaF}$ was first described as a bone-specific tracer in $1962(30)$, but not until the availability of modern PET and, subsequently, PET/CT scanners was it possible to take advantage of some of the superior physiologic and pharmacokinetic characteristics of this tracer compared with the ${ }^{99 \mathrm{~m}} \mathrm{Tc}$-based tracers used in conventional BS. The pharmacokinetics of ${ }^{18} \mathrm{~F}-\mathrm{NaF}$, including nearly $100 \%$ firstpass extraction into bone, negligible protein binding, and rapid renal excretion in hydrated subjects, allow early imaging of the skeletonat less than $1 \mathrm{~h}$ after injection-with high contrast and spatial resolution (13). The mechanism of uptake into bone is similar to that of ${ }^{99 \mathrm{~m}} \mathrm{Tc}$ diphosphonates, being related to local blood flow and osteoblastic activity, with rapid initial uptake and eventual incorporation into bone mineral as fluoroapatite.

Early studies showed the net clearance of ${ }^{18} \mathrm{~F}-\mathrm{NaF}$ in breast cancer skeletal metastases to be 3-10 times greater than that in normal bone, with the ability to detect osteolytic and osteosclerotic metastases $(31,32)$. PET and PET/CT studies in metastatic breast cancer have shown improved diagnostic accuracy compared with that of BS (33-37) or CT (38), and ${ }^{18} \mathrm{~F}-\mathrm{NaF}$ PET/CT has shown higher diagnostic accuracy than ${ }^{18} \mathrm{~F}-\mathrm{NaF}$ PET without the CT component (35). Similar improvements in diagnostic accuracy over that of BS with or without SPECT have been replicated in other cancers, including prostate cancer (39-41), lung cancer (42), renal cancer (43), bladder cancer (44), and hepatocellular carcinoma (45). Prospective studies with ${ }^{18} \mathrm{~F}-\mathrm{NaF}$ for the detection of bone metastases are in progress (NCT00882609 (46) and NCT01930812 (47)). A National Oncology PET Registry trial assessed the impact of ${ }^{18} \mathrm{~F}$ $\mathrm{NaF}$ PET/CT on the management of patients with cancer other than prostate cancer and included 781 patients with breast cancer (48). For the breast cancer patients, management changed for $24 \%$ of 


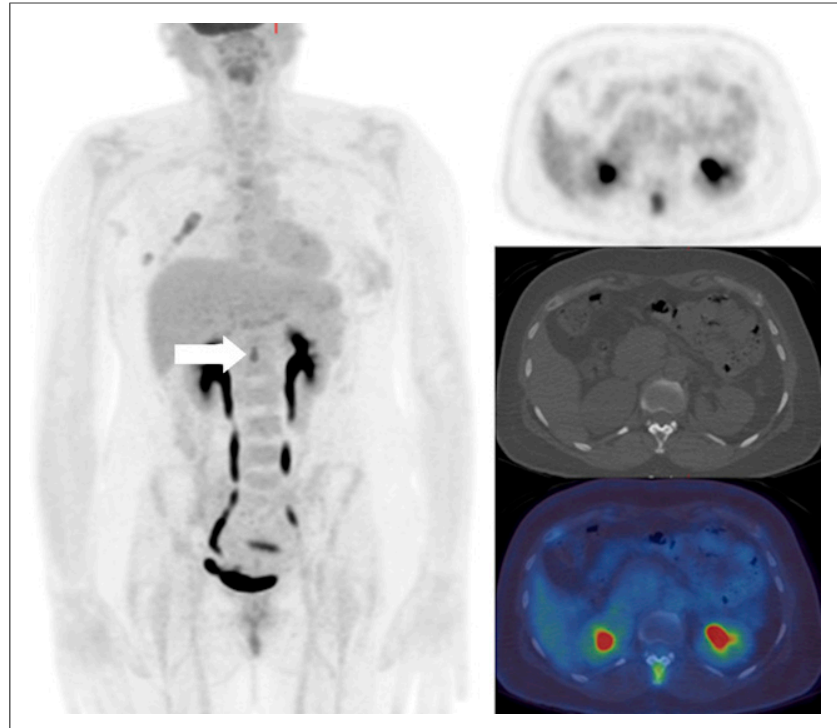

FIGURE 2. Maximum-intensity projection ${ }^{18} \mathrm{~F}-\mathrm{FDG}$ PET/CT and axial ${ }^{18} \mathrm{~F}-\mathrm{FDG}$ PET, CT, and fused PET/CT slices (right, from top to bottom) showing abnormal uptake in T12 spinous process (arrow) and at T4 in a 48-y-old woman with metastatic breast cancer (same patient as in Fig. 1).

those with suspected first osseous metastasis and for $60 \%$ of those with suspected progression of osseous metastasis.

Although we are not aware of prospective data on the use of ${ }^{18} \mathrm{~F}-\mathrm{NaF} \mathrm{PET} / \mathrm{CT}$ for the assessment of a treatment response in skeletal metastases from breast cancer, the feasibility of performing kinetic analysis of ${ }^{18} \mathrm{~F}-\mathrm{NaF}$ uptake in metastases and normal bone in patients with breast cancer has been confirmed (49), and preliminary studies in metastatic prostate cancer have shown

promise $(50,51)$. A further National Oncology PET Registry trial assessed the impact of ${ }^{18} \mathrm{~F}-\mathrm{NaF}$ PET/CT used for treatment monitoring and included 476 patients with breast cancer (52). The frequency of a change in the management plan for patients with breast cancer was $39.3 \%$. Of note, there have been preliminary reports of a flare phenomenon with ${ }^{18} \mathrm{~F}-\mathrm{NaF}$ PET after both chemotherapy and endocrine therapy in breast cancer; therefore, the timing of follow-up scans may be crucial (Figs. 1-3) (53,54).

\section{${ }^{18}$ F-FDG PET}

The uptake of ${ }^{18} \mathrm{~F}-\mathrm{FDG}$ in viable skeletal metastases is assumed to be predominantly within breast cancer tumor cells rather than osseous cells, such as osteoblasts or osteoclasts, thereby acting as a tumor-specific tracer rather than directly reflecting the altered bone microenvironment.

Several authors have reported lower sensitivity for ${ }^{18} \mathrm{~F}-\mathrm{FDG}$ PET in osteoblastic lesions than in osteolytic lesions $(15,17,55)$. Several factors may contribute to the reported differences in ${ }^{18} \mathrm{~F}-\mathrm{FDG}$ avidity between osteoblastic and osteolytic metastases. Metastases that are inherently more biologically aggressive may show higher ${ }^{18}$ F-FDG uptake, with patients having a shorter overall survival than those with osteoblastic disease (17). The underlying histologic subtype may also be important; untreated invasive lobular carcinoma has been reported to show osteoblastic metastases with poor ${ }^{18} \mathrm{~F}$-FDG uptake more frequently than invasive ductal or mixed subtypes (56). Previous treatment history is also important, as many ${ }^{18} \mathrm{~F}-\mathrm{FDG}$-negative skeletal metastases may appear sclerotic as a consequence of previous successful systemic therapy, rendering tumor cells nonviable-even though ongoing reparative osteoblastic activity, as seen with $\mathrm{BS}$ or ${ }^{18} \mathrm{~F}-\mathrm{NaF}$ PET, may persist (57).

For detection of skeletal metastases and staging of cancer, ${ }^{18} \mathrm{~F}$ FDG PET or PET/CT has shown higher sensitivity or specificity than BS in most reported studies $(58,59)$ and metaanalyses $(14,16,60)$. The improvement in sensitivity over that of BS

A

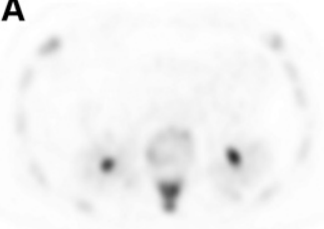

SUVmax $=21.5$
B

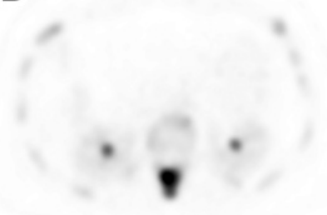

SUVmax $=51.6$

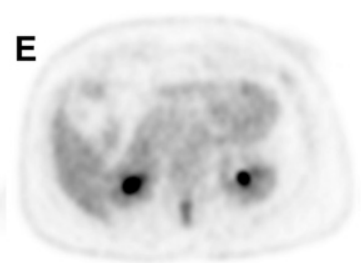

SUVmax $=4.0$

E
C

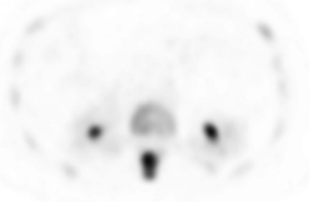

SUVmax $=33.9$

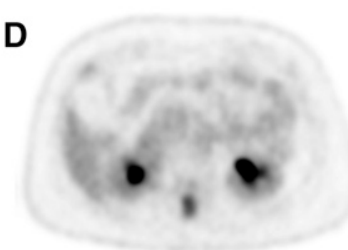

SUVmax $=5.7$
18

FIGURE 3. Axial slices at T12 showing ${ }^{18} \mathrm{~F}-\mathrm{NaF}$ PET at baseline $(\mathrm{A})$ and at $8 \mathrm{wk}(\mathrm{B})$ and $12 \mathrm{wk}(\mathrm{C})$ after commencement of endocrine treatment and equivalent ${ }^{18} \mathrm{~F}-\mathrm{FDG}$ slices at baseline (D) and at
$8 \mathrm{wk}(\mathrm{E})$ in a 48 -y-old woman with metastatic breast cancer (same patient as in Figs. 1 and 2). ${ }^{18} \mathrm{~F}-\mathrm{NaF}$ PET at 8 wk shows significant increase in SUV $\max$, whereas ${ }^{18} \mathrm{~F}-\mathrm{FDG}$ PET shows nearly $30 \%$ reduction in SUV $\mathrm{V}_{\max }{ }^{18} \mathrm{~F}-\mathrm{NaF}$ PET at 12 wk shows decrease in SUV $\max$ compared with that at $8 \mathrm{wk}$. This patient subsequently responded clinically, and scan sequences were interpreted as showing metabolic response with ${ }^{18} \mathrm{~F}-\mathrm{FDG}$ PET at 8 wk but flare with ${ }^{18} \mathrm{~F}-\mathrm{NaF}$ PET. may be due to the ability to detect metastatic tumor cells in the bone marrow before there is a sufficient osteoblastic effect to allow detection by bone-specific tracers. Gains in specificity may result from fewer causes of false-positive uptake of ${ }^{18} \mathrm{~F}-\mathrm{FDG}$ than of nonspecific bone tracers in the skeleton.

It has been postulated that coinjecting ${ }^{18} \mathrm{~F}-\mathrm{NaF}$ and ${ }^{18} \mathrm{~F}-\mathrm{FDG}$ may allow even better diagnostic accuracy than the injection of either tracer alone or consecutively (61$63)$. In a prospective multicenter study, separate ${ }^{18} \mathrm{~F}$-FDG PET/CT and ${ }^{18} \mathrm{~F}-\mathrm{NaF}$ PET/CT were compared with coinjected ${ }^{18} \mathrm{~F}-\mathrm{FDG} /{ }^{18} \mathrm{~F}-\mathrm{NaF}$ PET/CT in patients with various cancers. In the 39 breast cancer patients included in the study, the combined scan revealed more lesions than ${ }^{18} \mathrm{~F}-\mathrm{NaF}$ PET/CT alone, and in 5 patients, lesions that were not visible on ${ }^{18} \mathrm{~F}$-FDG PET/CT alone were revealed by the combined scan (63). In another study, softtissue lesion conspicuity was not adversely 


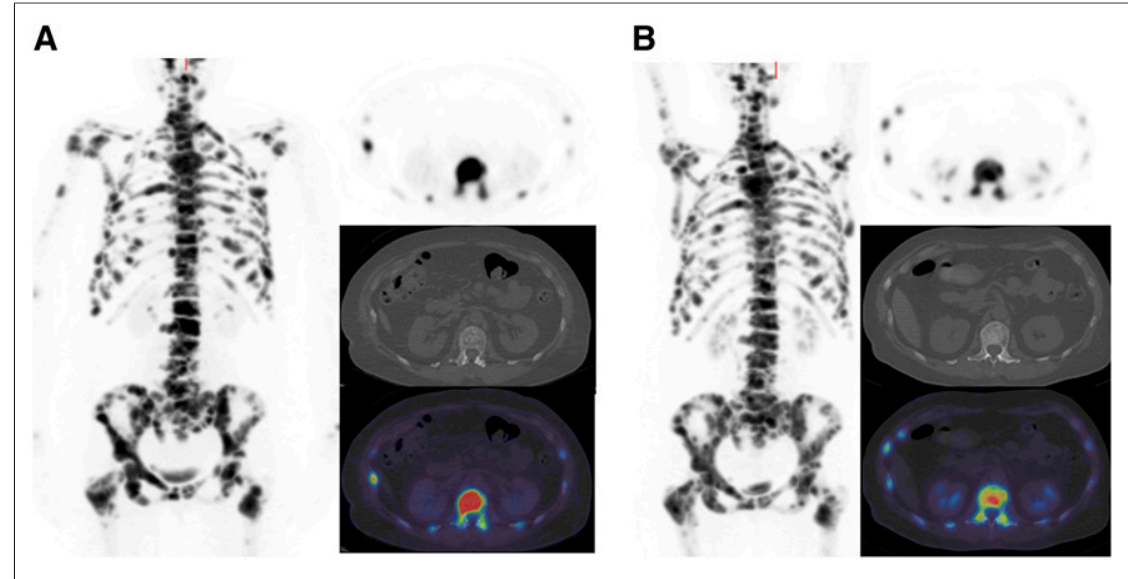

FIGURE 4. A 59-y-old woman with metastatic breast cancer. Maximum-intensity-projection ${ }^{18} \mathrm{~F}-\mathrm{NaF}$ (left) and axial ${ }^{18} \mathrm{~F}-\mathrm{NaF}$ PET, CT, and fused PET/CT (right, from top to bottom) at level of $L 1$ at baseline $(A)$ and at 8 wk (B) after commencement of endocrine therapy. Reduction in activity in all lesions was seen on ${ }^{18} \mathrm{~F}-\mathrm{NaF}$ PET (L1 SUV $\max$ decreased from 75.7 to 44.5).

model (67). Therefore, ${ }^{18}$ F-FDG PET seems to be able to add specificity to a purely morphologic treatment response assessment of bone metastases in breast cancer.

Further studies have shown that changes in ${ }^{18} \mathrm{~F}$-FDG SUV $\mathrm{max}_{\text {max }}$ correlate with clinical and tumor marker response assessments (68) and are predictive of time to progression and time to skeleton-related events (69). A correlation between response or progressive disease on ${ }^{18} \mathrm{~F}$-FDG PET and circulating tumor cell counts has also been observed (70). An ${ }^{18}$ F-FDG PET assessment was the only factor predictive of progression-free survival in a multivariate analysis, whereas estrogen receptor status was the only factor predictive of overall survival. In a prospective study of 22 patients (15 with bone metastases) receiving endocrine therapy for metastatic breast cancer, ${ }^{18} \mathrm{~F}-\mathrm{FDG}$ PET/CT was performed

affected when a combined scan was used, and although skeletal lesion-to-background ratios were lower than those obtained with ${ }^{18} \mathrm{~F}-\mathrm{NaF}$ alone, no skeletal lesions were missed on the combined scan (64).

There is accumulating evidence that ${ }^{18} \mathrm{~F}$-FDG PET may have the advantage over conventional imaging of being able to determine a response or a nonresponse to systemic therapeutics more accurately and at an earlier time point, with the potential to limit toxicity and accelerate the therapeutic transition in nonresponders. However, as yet there is no evidence that these properties translate into improved outcomes in terms of skeleton-related events, time to progression, or overall survival.

Compared with morphologic changes in bone lesions on CT, progressive lesions become more lytic and ${ }^{18} \mathrm{~F}-\mathrm{FDG}-\mathrm{avid}$, whereas increased sclerosis usually indicates a response but can also be seen with progression (65); such observations were also reported in a retrospective series (Figs. 4 and 5) (66). In another retrospective study, although both a change in the ${ }^{18} \mathrm{~F}-\mathrm{FDG} \mathrm{SUV}_{\max }$ and increased sclerosis on CT predicted time to progression in a univariate analysis, only the change in the $\mathrm{SUV}_{\max }$ remained predictive in a multivariate

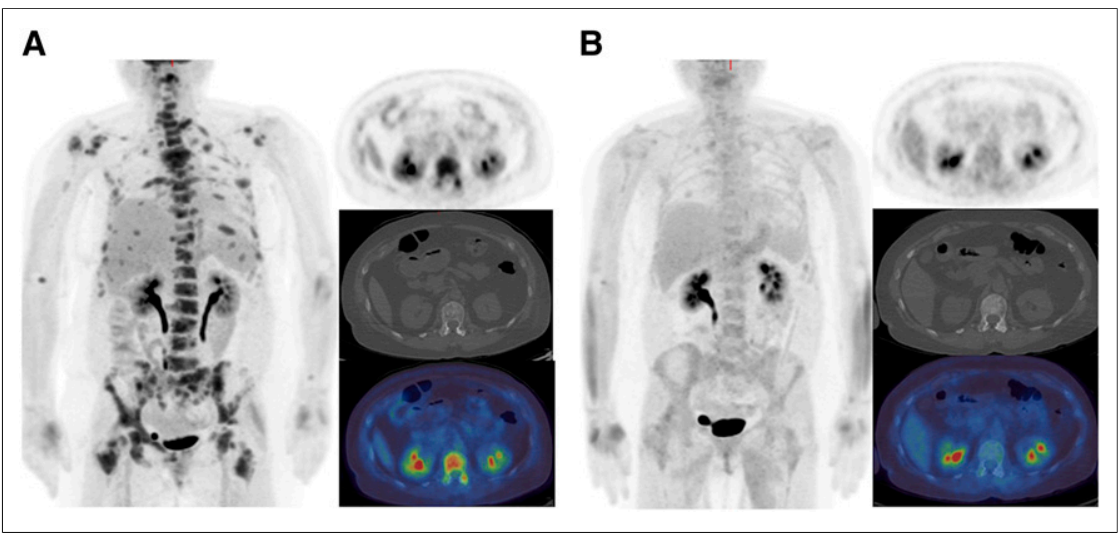

FIGURE 5. Maximum-intensity-projection ${ }^{18} \mathrm{~F}-\mathrm{FDG}$ PET/CT and axial slices at baseline (A) and at 8 wk (B) in 59-y-old woman with metastatic breast cancer (same patient as in Fig. 4). Marked metabolic response was seen on ${ }^{18} \mathrm{~F}$-FDG PET (L1 SUV $\max$ decreased from 9.5 to 3.3). Note increase in sclerosis in L1 on CT component. at baseline and at $10( \pm 4) \mathrm{wk}$, and European Organization for Research and Treatment of Cancer PET response criteria were used (71). The authors reported statistically significant differences in progression-free survival but not overall survival between patients with progressive metabolic disease and patients who did not show progression (either responders or stable disease) (72).

\section{OTHER MODALITIES}

Whole-body MRI is now feasible in scan times of less than $1 \mathrm{~h}$, and standard morphologic sequences (e.g., T1- and T2-weighted imaging and short-T1 inversion recovery imaging) are increasingly being combined with whole-body diffusion-weighted imaging. The signal from diffusion-weighted MRI (DW-MRI) depends on the rate of diffusion of water molecules, whereby tumors-which are typically hypercellular-show restricted diffusion compared with normal tissues. This property can be quantified, with the apparent diffusion coefficient representing the rate of signal loss with increasing diffusion weighting $(73,74)$. The apparent diffusion coefficient typically increases with successful therapy as a result of cytotoxicity, reduced cellularity, and loss of cell membrane integrity, allowing water molecules to be more freely diffusible. Sclerotic lesions return a low signal on T1- and T2-weighted images and, because of fewer water molecules, are associated with lower diffusion signal and apparent diffusion coefficient. Therefore, differentiating reparative sclerosis after successful treatment from progressive disease may remain difficult (75), as it is with $\mathrm{BS}$, although others have not shown this effect to be significant in prostate cancer (76).

In metastatic breast cancer, DW-MRI has been reported to be as sensitive as but less specific than ${ }^{18} \mathrm{~F}$-FDG PET/CT, particularly in lymph nodes and the skeleton. These results indicate that the functional images from DW-MRI should not be read in isolation; correlation with morphologic 
assessment is required (77). A metaanalysis of studies of bone metastases from various cancers confirmed high sensitivity (90\%) and specificity (92\%) for whole-body MRI with diffusion-weighted imaging but lower specificity in studies in which DW-MRI was included (18).

One of the first comparisons of ${ }^{18} \mathrm{~F}-\mathrm{FDG}$ PET/CT and PET/MRI in malignant skeletal disease, including 19 patients with breast cancer, reported similar lesion conspicuity and classification on PET but better anatomic delineation on MRI compared with CT (78). A systematic reduction in SUVs was noted in lesions and normal bone when PET/MRI was used; this issue is known to occur when MRI tissue segmentation methodology, which excludes cortical bone, is used for attenuation correction of PET data (79).

\section{CONCLUSION}

Although BS has served well for several decades, more recent advances in imaging have enabled several techniques to be used for staging of the skeleton with higher sensitivity and specificity. Some advances relate to hybrid imaging; for example, with SPECT/CT, PET/CT, and now PET/MRI, the high sensitivity of bone-specific or tumor-specific tracers can be complemented with the high spatial resolution and improved specificity of morphologic methods. At present, there are insufficient data to be able to determine which method provides the highest sensitivity for staging of the skeleton in breast cancer, but there is little doubt that the addition of CT in the form of BS with SPECT/CT and either bone-specific imaging with ${ }^{18} \mathrm{~F}$ $\mathrm{NaF}$ or tumor-specific imaging with ${ }^{18} \mathrm{~F}-\mathrm{FDG}$ and PET/CT improves diagnostic accuracy. It remains uncertain whether ${ }^{18} \mathrm{~F}-\mathrm{NaF}$ or ${ }^{18} \mathrm{~F}-\mathrm{FDG}$ alone is sufficiently sensitive for all subtypes of bone metastases or whether both tracers are required, possibly as a combination cocktail, to yield the highest sensitivity and specificity.

For monitoring of a treatment response, there are insufficient data to be able to recommend serial ${ }^{18} \mathrm{~F}-\mathrm{NaF}$ PET/CT in breast cancer, and it is likely that the flare phenomenon-as recognized with BS for many years-will also be a problem for early response assessment within a few months of the start of systemic therapy. In contrast, accumulating evidence suggests that ${ }^{18}$ F-FDG PET/CT may be a good method for measuring a response early in the course of therapy, perhaps as early as 2 or 3 mo. Whole-body MRI is now feasible and practical, although there remain insufficient data specifically about routine use for breast cancer skeletal metastases; further work is required to understand how to optimally use DW-MRI and the apparent diffusion coefficient to measure a treatment response. It is tempting to think that the combination of morphologic, metabolic, and physiologic data that PET/MRI supply may provide a step forward in this clinical application where it is recognized that current methods are insufficiently sensitive and specific at early time points.

\section{DISCLOSURE}

We acknowledge financial support from the Department of Health (England) via National Institute for Health Research (NIHR) Biomedical Research Centre awards to Guy's and St. Thomas' NHS Foundation Trust in partnership with King's College London and the King's College London/University College London Compre- hensive Cancer Imaging Centre funded by Cancer Research UK and the Engineering and Physical Sciences Research Council in association with the Medical Research Council and the Department of Health and a research grant from Breast Cancer Now. No other potential conflict of interest relevant to this article was reported.

\section{REFERENCES}

1. Jung SY, Rosenzweig M, Sereika S, Linkov F, Brufsky A, Weissfeld JL. Factors associated with mortality after breast cancer metastasis. Cancer Causes Control. 2012;23:103-112.

2. Manders K, van de Poll-Franse LV, Creemers G-J, et al. Clinical management of women with metastatic breast cancer: a descriptive study according to age group. BMC Cancer. 2006;6:179.

3. Plunkett TA, Smith P, Rubens RD. Risk of complications from bone metastases in breast cancer: implications for management. Eur J Cancer. 2000;36: $476-482$.

4. Wei S, Li Y, Siegal GP, Hameed O. Breast carcinomas with isolated bone metastases have different hormone receptor expression profiles than those with metastases to other sites or multiple organs. Ann Diagn Pathol. 2011;15: 79-83.

5. Domchek SM, Younger J, Finkelstein DM, Seiden MV. Predictors of skeletal complications in patients with metastatic breast carcinoma. Cancer. 2000;89: 363-368.

6. Hayward JL, Carbone PP, Heusen JC, Kumaoka S, Sealoff A, Rubens RD. Assessment of response to therapy in advanced breast cancer. $\mathrm{Br} J$ Cancer. 1977;35:292-298

7. World Health Organization. WHO Handbook for Reporting Results of Cancer Treatment. Geneva, Switzerland: World Health Organization; 1979:24-25. WHO Offset Publication No. 48.

8. Eisenhauer EA, Therasse P, Bogaerts J, et al. New response evaluation criteria in solid tumours: revised RECIST guideline (version 1.1). Eur J Cancer. 2009;45: 228-247.

9. Hamaoka T, Costelloe CM, Madewell JE, et al. Tumour response interpretation with new tumour response criteria vs the World Health Organisation criteria in patients with bone-only metastatic breast cancer. Br J Cancer. 2010;102: 651-657.

10. Hayashi N, Costelloe CM, Hamaoka T, et al. A prospective study of bone tumor response assessment in metastatic breast cancer. Clin Breast Cancer. 2013;13:24-30.

11. Paget S. The distribution of secondary growth in cancer of the breast. Lancet. 1889;1:571-573.

12. Guise TA, Mohammad KS, Clines G, et al. Basic mechanisms responsible for osteolytic and osteoblastic bone metastases. Clin Cancer Res. 2006;12:6213s$6216 \mathrm{~s}$.

13. Blake GM, Park-Holohan SJ, Cook GJ, Fogelman I. Quantitative studies of bone with the use of ${ }^{18} \mathrm{~F}$-fluoride and ${ }^{99} \mathrm{~m}$ Tc-methylene diphosphonate. Semin Nucl Med. 2001;31:28-49.

14. Shie P, Cardarelli R, Brandon D, Erdman W, Abdulrahim N. Meta-analysis: comparison of F-18 fluorodeoxyglucose-positron emission tomography and bone scintigraphy in the detection of bone metastases in patients with breast cancer. Clin Nucl Med. 2008;33:97-101.

15. Abe K, Sasaki M, Kuwabara Y, et al. Comparison of ${ }^{18}$ FDG-PET with ${ }^{99 m} \mathrm{Tc}-$ HMDP scintigraphy for the detection of bone metastases in patients with breast cancer. Ann Nucl Med. 2005;19:573-579.

16. Rong J, Wang S, Ding Q, Yun M, Zheng Z, Ye S. Comparison of ${ }^{18}$ FDG PET-CT and bone scintigraphy for detection of bone metastases in breast cancer patients: a meta-analysis. Surg Oncol. 2013;22:86-91.

17. Cook GJ, Houston S, Rubens R, Maisey MN, Fogelman I. Detection of bone metastases in breast cancer by FDG PET: differing metabolic activity in osteoblastic and osteolytic lesions. J Clin Oncol. 1998;16:3375-3379.

18. Wu LM, Gu HY, Zheng J, et al. Diagnostic value of whole-body magnetic resonance imaging for bone metastases: a systematic review and meta-analysis. J Magn Reson Imaging. 2011;34:128-135.

19. Even-Sapir E, Martin RH, Barnes DC, Pringle CR, Iles SE, Mitchell MJ. Role of SPECT in differentiating malignant from benign lesions in the lower thoracic and lumbar vertebrae. Radiology. 1993;187:193-198.

20. Savelli G, Maffioli L, Maccauro M, de Deckere E, Bombardieri E. Bone scintigraphy and the added value of SPECT (single photon emission tomography) in detecting skeletal lesions. $Q$ J Nucl Med. 2001;45:27-37.

21. Han LJ, Au-Yong TK, Tong WCM, Chu KS, Szeto LT, Wong CP. Comparison of bone single-photon emission tomography and planar imaging in the detection of vertebral metastases in patients with back pain. Eur J Nucl Med. 1998;25:635-638. 
22. Sharma P, Singh H, Kumar R, et al. Bone scintigraphy in breast cancer: added value of hybrid SPECT-CT and its impact on patient management. Nucl Med Commun. 2012;33:139-147.

23. Utsunomiya D, Shiraishi S, Imuta M, et al. Added value of SPECT/CT fusion in assessing suspected bone metastasis: comparison with scintigraphy alone and non-fused scintigraphy and CT. Radiology. 2006;238:264-271.

24. Palmedo H, Marx C, Ebert A, et al. Whole-body SPECT/CT for bone scintigraphy: diagnostic value and effect on patient management in oncological patients. Eur J Nucl Med Mol Imaging. 2014;41:59-67.

25. Uematsu T, Yuen S, Yukisawa S, et al. Comparison of FDG PET and SPECT for detection of bone metastases in breast cancer. AJR. 2005;184: $1266-1273$

26. Coombes RC, Dady P, Parsons C, et al. Assessment of response of bone metastases to systemic treatment in patients with breast cancer. Cancer. 1983;52: 610-614.

27. Schneider JA, Divgi CR, Scott AM, et al. Flare on bone scintigraphy following Taxol chemotherapy for metastatic breast cancer. J Nucl Med. 1994;35:17481752 .

28. Vogel CL, Schoenfelder J, Shemano I, Hayes DF, Gams RA. Worsening bone scan in the evaluation of antitumor response during hormonal therapy of breast cancer. J Clin Oncol. 1995;13:1123-1128.

29. Coleman RE, Mashiter G, Whitaker KB, Moss DW, Rubens RD, Fogelman I. Bone scan flare predicts successful systemic therapy for bone metastases. $\mathrm{J} \mathrm{Nucl}$ Med. 1988;29:1354-1359.

30. Blau M, Nagler W, Bender MA. Fluorine-18: a new isotope for bone scanning. J Nucl Med. 1962;3:332-334.

31. Petrén-Mallmin M, Andréasson I, Ljunggren Ö, et al. Skeletal metastases from breast cancer: uptake of ${ }^{18} \mathrm{~F}$-fluoride measured with positron emission tomography in correlation with CT. Skeletal Radiol. 1998;27:72-76.

32. Hawkins RA, Choi Y, Huang SC, et al. Evaluation of the skeletal kinetics of fluorine-18-fluoride ion with PET. J Nucl Med. 1992;33:633-642.

33. Schirrmeister H, Guhlmann A, Kotzerke J, et al. Early detection and accurate description of extent of metastatic bone disease in breast cancer with fluoride ion and positron emission tomography. J Clin Oncol. 1999;17: 2381-2389.

34. Withofs N, Grayet B, Tancredi T, et al. ${ }^{18} \mathrm{~F}$-fluoride PET/CT for assessing bone involvement in prostate and breast cancers. Nucl Med Commun. 2011;32:168176.

35. Even-Sapir E, Metser U, Flusser G, et al. Assessment of malignant skeletal disease: initial experience with ${ }^{18} \mathrm{~F}$-fluoride PET/CT and comparison between ${ }^{18}$ F-fluoride PET and ${ }^{18}$ F-fluoride PET/CT. J Nucl Med. 2004;45: $272-278$.

36. Damle NA, Bal C, Bandopadhyaya GP, et al. The role of ${ }^{18} \mathrm{~F}$-fluoride PET-CT in the detection of bone metastases in patients with breast, lung and prostate carcinoma: a comparison with FDG PET/CT and $99 \mathrm{mTc}$ TDP bone scan. Jpn J Radiol. 2013;31:262-269.

37. Yoon SH, Kim KS, Kang SY, et al. Usefulness of ${ }^{18}$ F-fluoride PET/CT in breast cancer patients with osteosclerotic bone metastases. Nucl Med Mol Imaging. 2013;47:27-35.

38. Piccardo A, Altrinetti V, Bacigalupo L, et al. Detection of metastatic bone lesions in breast cancer patients: fused ${ }^{18} \mathrm{~F}$-fluoride-PET/MDCT has higher accuracy than MDCT-preliminary experience. Eur J Radiol. 2012;81: 2632-2638.

39. Even-Sapir E, Metser U, Mishani E, Lievshitz G, Lerman H, Leibovitch I. The detection of bone metastases in patients with high-risk prostate cancer: ${ }^{99 \mathrm{~m}} \mathrm{Tc}-\mathrm{MDP}$ planar bone scintigraphy, single- and multi-field-of-view SPECT, ${ }^{18}$ F-fluoride PET, and ${ }^{18}$ F-fluoride PET/CT. J Nucl Med. 2006; 47: 287-297.

40. Kjölhede H, Ahlgren G, Almquist H, et al. Combined ${ }^{18} \mathrm{~F}$-fluorocholine and ${ }^{18} \mathrm{~F}$ fluoride positron emission tomography/computed tomography imaging for staging of high-risk prostate cancer. BJU Int. 2012;110:1501-1506.

41. Langsteger W, Balogova S, Huchet V, et al. Fluorocholine $\left({ }^{18} \mathrm{~F}\right)$ and sodium fluoride $\left({ }^{18} \mathrm{~F}\right) \mathrm{PET} / \mathrm{CT}$ in the detection of prostate cancer: prospective comparison of diagnostic performance determined by masked reading. $Q \mathrm{~J} \mathrm{Nucl} \mathrm{Med}$ Mol Imaging. 2011;55:448-457.

42. Hetzel M, Arslandemir C, König HH, et al. F-18 NaF PET for detection of bone metastases in lung cancer: accuracy, cost-effectiveness, and impact on patient management. J Bone Miner Res. 2003;18:2206-2214.

43. Sharma P, Karunanithi S, Chakraborty PS, et al. ${ }^{18}$ F-fluoride PET/CT for detection of bone metastasis in patients with renal cell carcinoma: a pilot study. Nucl Med Commun. 2014;35:1247-1253.

44. Chakraborty D, Bhattacharya A, Mete UK, Mittal BR. Comparison of ${ }^{18} \mathrm{~F}$ fluoride PET/CT and ${ }^{99 \mathrm{~m}} \mathrm{Tc}-\mathrm{MDP}$ bone scan in the detection of skeletal metastases in urinary bladder carcinoma. Clin Nucl Med. 2013;38:616-621.
45. Yen RF, Chen CY, Cheng MF, et al. The diagnostic and prognostic effectiveness of F-18 sodium fluoride PET-CT in detecting bone metastases for hepatocellular carcinoma patients. Nucl Med Commun. 2010;31: 637-645.

46. F18PET/CT versus TC-MDP scanning to detect bone mets. ClinicalTrials.gov website. https://clinicaltrials.gov/ct2/show/NCT00882609?term $=$ NCT00882609\& rank=1. Verified November 2012. Accessed September 21, 2015.

47. ${ }^{18} \mathrm{~F}-\mathrm{NaF}$ PET imaging for bone scintigraphy. ClinicalTrials.gov website. https:// clinicaltrials.gov/ct2/show/NCT01930812?term $=$ NCT01930812\&rank=1. Verified July 2015. Accessed September 21, 2015.

48. Hillner BE, Siegel BA, Hanna L, et al. Impact of ${ }^{18} \mathrm{~F}$-fluoride PET on intended management of patients with cancers other than prostate cancer: results from the National Oncologic PET Registry. J Nucl Med. 2014;55: 1054-1061.

49. Doot RK, Muzi M, Peterson LM, et al. Kinetic analysis of ${ }^{18}$ F-fluoride PET images of breast cancer bone metastases. J Nucl Med. 2010;51:521-527.

50. Cook GJR, Parker C, Chua S, Johnson B, Aksnes AK, Lewington VJ. ${ }^{18} \mathrm{~F}-$ fluoride PET: changes in uptake as a method to assess response in bone metastases from castrate-resistant prostate cancer patients treated with ${ }^{223} \mathrm{Ra}$-chloride (Alpharadin). EJNMMI Res. 2011;1:4.

51. Yu EY, Duan F, Muzi M, et al. Castration-resistant prostate cancer bone metastasis response measured by ${ }^{18} \mathrm{~F}$-fluoride PET after treatment with dasatinib and correlation with progression-free survival: results from American College of Radiology Imaging Network 6687. J Nucl Med. 2015;56: 354-360.

52. Hillner BE, Siegel BA, Hanna L, Duan F, Quinn B, Shields AF. ${ }^{18}$ F-fluoride PET used for treatment monitoring of systemic cancer therapy: results from the National Oncologic PET Registry. J Nucl Med. 2015;56:222-228.

53. Wade AA, Scott JA, Kuter I, Fischman AJ. Flare response in ${ }^{18} \mathrm{~F}$-fluoride ion PET bone scanning. AJR. 2006;186:1783-1786.

54. Cook GJ, Taylor BP, Glendenning J, et al. Heterogeneity of treatment response in skeletal metastases from breast cancer in ${ }^{18} \mathrm{~F}$-fluoride and ${ }^{18} \mathrm{~F}$-FDG PET. $\mathrm{Nucl}$ Med Commun. 2015;36:515-516.

55. Nakai T, Okuyama C, Kubota T, et al. Pitfalls of FDG-PET for the diagnosis of osteoblastic bone metastases in patients with breast cancer. Eur J Nucl Med Mol Imaging. 2005;32:1253-1258.

56. Dashevsky BZ, Goldman DA, Parsons M, et al. Appearance of untreated bone metastases from breast cancer on FDG PET/CT: importance of histologic subtype. Eur J Nucl Med Mol Imaging. 2015;42:1666-1673.

57. Israel O, Goldberg A, Nachtigal A, et al. FDG-PET and CT patterns of bone metastases and their relationship to previously administered anti-cancer therapy. Eur J Nucl Med Mol Imaging. 2006;33:1280-1284.

58. Hahn S, Heusner T, Kümmel S, et al. Comparison of FDG-PET/CT and bone scintigraphy for detection of bone metastases in breast cancer. Acta Radiol. 2011;52:1009-1014.

59. Ohta M, Tokuda Y, Suzuki Y, et al. Whole body PET for the evaluation of bony metastases in patients with breast cancer: comparison with 99Tcm-MDP bone scintigraphy. Nucl Med Commun. 2001;22:875-879.

60. Liu T, Cheng T, Xu W, et al. A meta-analysis of ${ }^{18}$ FDG-PET, MRI and bone scintigraphy for diagnosis of bone metastases in patients with breast cancer. Skeletal Radiol. 2011;40:523-531.

61. Hoegerle S, Juengling F, Otte A, Altehoefer C, Moser EA, Nitzsche EU. Combined FDG and [F-18]fluoride whole-body PET: a feasible two-in-one approach to cancer imaging? Radiology. 1998;209:253-258.

62. Sampath SC, Sampath SC, Mosci C, et al. Detection of osseous metastasis by ${ }^{18} \mathrm{~F}-\mathrm{NaF} /{ }^{18} \mathrm{~F}-\mathrm{FDG}$ PET/CT versus CT alone. Clin Nucl Med. 2015;40:e173-e177.

63. Iagaru A, Mittra E, Mosci C, et al. Combined ${ }^{18} \mathrm{~F}$-fluoride and ${ }^{18} \mathrm{~F}-\mathrm{FDG}$ PET/CT scanning for evaluation of malignancy: results of an international multicenter trial. J Nucl Med. 2013;54:176-183.

64. Minamimoto R, Mosci C, Jamali M, et al. Semiquantitative analysis of the biodistribution of the combined ${ }^{18} \mathrm{~F}-\mathrm{NaF}$ and ${ }^{18} \mathrm{~F}-\mathrm{FDG}$ administration for PET/ CT imaging. J Nucl Med. 2015;56:688-694.

65. Katayama T, Kubota K, Machida Y, Toriihara A, Shibuya H. Evaluation of sequential FDG-PET/CT for monitoring bone metastasis of breast cancer during therapy: correlation between morphological and metabolic changes with tumor markers. Ann Nucl Med. 2012;26:426-435.

66. Du Y, Cullum I, Illidge TM, Ell PJ. Fusion of metabolic function and morphology: sequential $\left[{ }^{18} \mathrm{~F}\right]$ fluorodeoxyglucose positron-emission tomography/computed tomography studies yield new insights into the natural history of bone metastases in breast cancer. J Clin Oncol. 2007;25:3440-3447.

67. Tateishi U, Gamez C, Dawood S, Yeung HW, Cristofanilli M, Macapinlac HA. Bone metastases in patients with metastatic breast cancer: morphologic and metabolic monitoring of response to systemic therapy with integrated PET/CT. Radiology. 2008;247:189-196. 
68. Stafford SE, Gralow JR, Schubert EK, et al. Use of serial FDG PET to measure the response of bone-dominant breast cancer to therapy. Acad Radiol. 2002;9: 913-921.

69. Specht JM, Tam SL, Kurland BF, et al. Serial 2- $\left[{ }^{18} \mathrm{~F}\right]$ fluoro-2-deoxy-D-glucose positron emission tomography (FDG-PET) to monitor treatment of bone-dominant metastatic breast cancer predicts time to progression (TTP). Breast Cancer Res Treat. 2007;105:87-94.

70. De Giorgi U, Mego M, Rohren EM, et al. ${ }^{18}$ F-FDG PET/CT findings and circulating tumor cell counts in the monitoring of systemic therapies for bone metastases from breast cancer. J Nucl Med. 2010;51:1213-1218.

71. Young H, Baum R, Cremerius U, et al. Measurement of clinical and subclinical tumour response using $\left[{ }^{18} \mathrm{~F}\right]$-fluorodeoxyglucose and positron emission tomography: review and 1999 EORTC recommendations. European Organization for Research and Treatment of Cancer (EORTC) PET Study Group. Eur J Cancer. 1999;35:1773-1782.

72. Mortazavi-Jehanno N, Giraudet AL, Champion L, et al. Assessment of response to endocrine therapy using FDG PET/CT in metastatic breast cancer: a pilot study. Eur J Nucl Med Mol Imaging. 2012;39:450-460.

73. Padhani AR, Makris A, Gall P, Collins DJ, Tunariu N, de Bono JS. Therapy monitoring of skeletal metastases with whole-body diffusion MRI. J Magn Reson Imaging. 2014;39:1049-1078.
74. Lecouvet FE, Talbot JN, Messiou C, et al. Monitoring the response of bone metastases to treatment with magnetic resonance imaging and nuclear medicine techniques: a review and position statement by the European Organization for Research and Treatment of Cancer imaging group. Eur J Cancer. 2014;50:25192531.

75. Reischauer C, Froehlich JM, Koh DM, et al. Bone metastases from prostate cancer: assessing treatment response by using diffusion-weighted imaging and functional diffusion maps-initial observations. Radiology. 2010;257:523-531.

76. Messiou C, Collins DJ, Morgan VA, Bianchini D, de Bono JS, de Souza NM. Use of apparent diffusion coefficient as a response biomarker in bone: effect of developing sclerosis on quantified values. Skeletal Radiol. 2014;43:205-208.

77. Heusner TA, Kuemmel S, Koeninger A, et al. Diagnostic value of diffusionweighted magnetic resonance imaging (DWI) compared to FDG PET/CT for whole-body breast cancer staging. Eur J Nucl Med Mol Imaging. 2010;37: 1077-1086.

78. Eiber M, Takei T, Souvatzoglou M, et al. Performance of whole-body integrated ${ }^{18}$ F-FDG PET/MR in comparison to PET/CT for evaluation of malignant bone lesions. J Nucl Med. 2014;55:191-197.

79. Bezrukov I, Schmidt H, Mantlik F, et al. MR-based attenuation correction methods for improved PET quantification in lesions within bone and susceptibility artifact regions. J Nucl Med. 2013;54:1768-1774. 